\title{
Status Keberlanjutan Wilayah Peternakan Sapi Potong untuk Pengembangan Kawasan Agropolitan di Kabupaten Bondowoso
}

\author{
Sustainability Status of Beef Cattle Farming for Developing Agropolitan Area \\ in Bondowoso
}

\author{
D.R. Ramadhan ${ }^{1}$, Nindyantoro ${ }^{2}$, dan Suyitman ${ }^{3}$ \\ ${ }^{1}$ Program Studi Pengelolaan Sumberdaya Alam dan Lingkungan IPB \\ Jalan Raya Padjadjaran Kampus IPB Baranangsiang Bogor \\ ${ }^{2}$ Departemen Ekonomi Sumberdaya Lingkungan Fakultas Ekonomi dan Manajemen IPB \\ Jalan Kamper Kampus IPB Dramaga Bogor \\ ${ }^{3}$ Bagian Nutrisi dan Teknologi Pakan Fakultas Peternakan Universitas Andalas \\ Kampus Unand Limau Manis Padang \\ e-Mail: dear.bgr@gmail.com \\ (Diterima: 7 Februari 2014; Disetujui: 27 Mei 2014)
}

\begin{abstract}
ABSTRAK
Penelitian bertujuan untuk menganalisis dua hal; (1) status indeks keberlanjutan dan (2) lima dimensi keberlanjutan pembangunan agropolitan. Penentuan status keberlanjutan menggunakan Multidimensional Scaling (MDS) dengan pendekatan Penilaian Cepat Agropolitan (RapAGROSAPOT). Atribut sensitif mempengaruhi indeks keberlanjutan dan efek kesalahan ditentukan berdasarkan Leverage analisis dan uji Monte Carlo. Penentuan faktor kunci keberlanjutan diperoleh dengan analisis prospektif. Hasil analisis keberlanjutan menunjukkan bahwa dimensi ekologi $(41,61 \%)$ dan infrastruktur teknologi $(47,05 \%)$ statusnya kurang berkelanjutan. Dimensi ekonomi $(57,73 \%)$ dan sosial budaya $(58,05 \%)$ serta dimensi hukumkelembagaan $(75,46 \%)$ statusnya cukup baik. Berdasarkan analisis pada 70 atribut; ada 24 atribut sensitif yang perlu diperbaiki karena efek peningkatan nilai indeks keberlanjutan. Analisis prospektif menghasilkan lima faktor kunci daerah keberlanjutan, yaitu: (a) ketersediaan sarana dan prasarana agribisnis peternakan, (b) sistem pemeliharaan ternak, (c) ketersediaan pasar agro-ternak, (d) ketersediaan industri pakan, dan (e) sapi milik koperasi. Perbaikan peternakan sapi agropolitan merupakan basis utama untuk pengembangan Kabupaten Bondowoso kedepan.
\end{abstract}

Kata kunci : sapi potong, keberlanjutan, agropolitan, Kabupaten Bondowoso

\section{ABSTRACT}

There were two objectives of research; (1) to analyze the status of the sustainability index and (2) to analyze five dimensions of sustainability for developing agropolitan in Bondowoso. Position of the status of sustainability was determined by Multidimensional Scaling (MDS) with Rapid Appraisal approach Agropolitan (Rap-AGROSAPOT). Sensitive attributes affected the sustainability index and the error effect was determined by Leverage and Monte Carlo test basis. The key sustainability factors were obtained by prospective analysis. Analysis of sustainability showed that the status of ecological dimension (41.61\%) and infrastructuretechnology (47.05\%) were less sustainable. The economic dimension (57.73\%) and socio-cultural (58.05\%) as well as the legal-institutional dimension (75.46\%) were good. Based on the 70 attributes analyzed, there were 24 sensitive attributes need to be improved due to an increasing effect on the value of sustainability index. Prospective analysis resulted five key factors of sustainability areas: (a) facilities and infrastructure of agribusiness availability, (b) rearing systems of livestock, (c) agro-livestock market facilities, (d) feed industry aviability, and (e) 
cooperative owned cattle. The key factors to achieve an agropolitan regency was a committed development of beef cattle farms.

Keywords : beef cattle, sustainability, agropolitan, Bondowoso Regency

\section{PENDAHULUAN}

Pembangunan pertanian harus mampu bersinergi dengan tujuan pembangunan wilayah perdesaan, yaitu meningkatkan taraf kehidupan sosial dan ekonomi masyarakat. Tujuan tersebut dapat tercapai melalui pengembangan kawasan potensial berbasiskan perdesaan sebagai pusat pertumbuhan dengan merubah perdesaan menjadi kota pertanian atau dikenal dengan Pengembangan Kawasan Agropolitan. Agropolitan adalah kota pertanian yang tumbuh dan berkembang dengan sistem agribisnis sehingga mampu melayani, mendorong, menarik, dan menghela kegiatan pembangunan pertanian di wilayah sekitarnya (Deptan, 2002).

Kabupaten Bondowoso merupakan daerah agraris. Beberapa tahun terakhir lahan pertanian di kabupaten itu menghadapi permasalahan serius, yaitu berkurangnya ketersediaan pasokan air dari sungai-sungai irigasi sebagai sumber pengairan lahan pertanian. Permasalahan ini terjadi karena kerusakan hutan di daerah hulu sungai. Petani yang sebelumnya mampu bercocok tanam sepanjang tahun ( 3 kali per tahun), saat ini hanya mampu bercocok tanam sebanyak 1-2 kali dalam setahun. Berkurangnya aktivitas bercocok tanam mengurangi penerimaan para petani, untuk mengatasi hal itu banyak petani yang beternak secara tradisional (ekstensif) maupun semi intensif dalam rangka peningkatan penerimaan.

Antusiasme masyarakat Kabupaten Bondowoso sangat tinggi terhadap sub-sektor peternakan, khususnya peternakan sapi potong (Sapi Simental, Hereford, Limousin, Brahman, Brangus, dan Peranakan Onggole). Keuntungan dari usaha ternak sapi potong cukup menjanjikan dibandingkan dengan keuntungan dari bercocok tanam. Selain itu, harga sarana produksi pertanian yang semakin meningkat dan ketersediaan lahan pertanian yang semakin berkurang membuat usaha ternak sapi potong semakin menarik untuk dilakukan. Populasi ternak sapi potong dalam kurun waktu tiga tahun terakhir mulai dari tahun 2009-2011 menunjukkan peningkatan cukup signifikan, yaitu: 135 093, 141 792, dan 203794 ekor (BPS Kabupaten Bondowoso, 2012).

Manfaat optimal diperoleh apabila pengembangan pengelolaan peternakan memenuhi kriteria pembangunan berkelanjutan (sustainable development) yang mempersekutukan antara kepentingan ekonomi, sosial budaya, dan kelestarian ekologi (Saragih dan Sipayung, 2002; Suyitman et al., 2009). Berkaitan dengan hal tersebut, perlu dikaji status keberlanjutan wilayah berbasiskan peternakan sapi potong di Kabupaten Bondowoso untuk pengembangan kawasan agropolitan. Manfaat dari hasil penelitian ini dapat dijadikan acuan dan bahan pertimbangan bagi pengambil kebijakan, khususnya pemerintah Kabupaten Bondowoso, dalam rangka meningkatkan status keberlanjutan wilayah berbasiskan peternakan sapi potong di Kabupaten Bondowoso untuk pengembangan kawasan agropolitan.

\section{METODE}

Penelitian dilakukan pada lima kecamatan di Kabupaten Bondowoso Propinsi Jawa Timur. Kriteria penetapan lokasi penelitian didasarkan atas: populasi ternak sapi potong, ketersediaan sumber pakan, dan aksesibilitas kawasan. Berdasarkan pertimbangan kriteria tersebut, terpilih lima kecamatan, yaitu: Kecamatan Cerme, Wringin, Maesan, Botolinggo, dan Tapen. Waktu penelitian dimulai bulan Januari sampai Juni 2014.

Data yang digunakan adalah data sekunder dan data primer. Data sekunder diperoleh melalui studi kepustakaan. Data primer diperoleh dari pengisian kuisioner oleh peternak dan hasil pendapat para pakar. 
Kriteria penentuan pakar terpilih, yaitu: (a) memiliki pengalaman dan kompetensi sesuai bidang dikaji, (b) memiliki reputasi dan jabatan dalam kompetensinya dengan bidang yang dikaji dan menunjukkan kredibilitasnya sebagai pakar, (c) memiliki komitmen pada permasalahan yang dikaji, (d) bersifat netral dan bersedia menerima pendapat responden lain, (e) bersedia dimintai pendapat dan berada pada lokasi penelitian.

\section{Metode Analisis}

Analisis keberlanjutan pengembangan kawasan agropolitan dilakukan dengan teknik multidimensional scaling (MDS) yang disebut pendekatan Rap-AGROSAPOT (Rapid Appraisal Agropolitan Sapi Potong). Metode ini adalah pengembangan dari pendekatan Rapfish yang digunakan untuk menilai status keberlanjutan perikanan tangkap (Kavanagh, 2001). Hasil analisis keberlanjutan dinyatakan dalam Indeks Keberlanjutan Agropolitan Sapi Potong (ikb-AGROSAPOT). Analisis data dilakukan melalui beberapa tahapan. Pertama, penentuan atribut yang mencakup lima dimensi keberlanjutan. Secara keseluruhan terdapat 70 atribut yang dianalisis, masingmasing: 20 atribut dimensi ekologi, 17 atribut dimensi ekonomi, 13 atribut dimensi sosial budaya, 12 atribut dimensi teknologi dan infrastruktur serta 8 atribut dimensi hukum dan kelembagaan. Kedua, penilaian setiap atribut dalam skala ordinal berdasarkan kriteria keberlanjutan setiap dimensi. Ketiga, penyusunan indeks dan status keberlanjutan kawasan baik secara multidimensi maupun pada setiap dimensi. Keempat, analisis kepekaan (leverage analysis) untuk menentukan peubah sensitif terhadap keberlanjutan. Kelima, Analisis Monte Carlo untuk memperhitungkan aspek ketidakpastian (Barlas, 2005 dan Gao et al., 2008).

Seluruh data dari atribut keberlanjutan selanjutnya dianalisis secara multidimensional untuk menentukan titik posisi keberlanjutan relatif terhadap dua titik acuan, yaitu titik "baik" (good) dan "buruk" (bad). Posisi titik keberlanjutan pembangunan ini secara visual sulit dipetakan. Oleh karena itu, untuk memudahkan visualisasi posisi ini digunakan analisis ordinasi dengan metode MDS (Suyitman et al., 2012). Menurut Fauzi dan Anna (2005), MDS pada Rapfish diterapkan dengan menghitung jarak terdekat dari $E u$ clidean distance pada persamaan (1.1) berikut:

$$
\begin{aligned}
& d_{1,2}=\sqrt{\left(x_{1}-x_{2}\right)^{2}+\left(y_{1}-y_{2}\right)^{2}+\ldots \ldots} \\
& d_{1,2}=\sqrt{\left(x_{1}-x_{2}\right)^{2}+\left(y_{1}-y_{2}\right)^{2}+\ldots \ldots}
\end{aligned}
$$

Jarak Euclidean multidimensi antara dua titik tersebut $\left(\mathrm{d}_{1,2}\right)$ kemudian diproyeksikan ke dalam jarak Euclidean dua dimensi $\left(\mathrm{D}_{12}\right)$ berdasarkan rumus regresi pada persamaan (1.2) berikut:

$$
\mathrm{d}_{12}=\mathrm{a}+\mathrm{b} \mathrm{D}_{12}+\mathrm{e} \text {; e adalah error. }
$$

Regresi tersebut menerapkan algoritma ALSCAL dengan proses pengulangan (iterasi) untuk mendapat nilai error terkecil. Menurut Kavanagh (2001) algoritma ALSCAL yang diterapkan memaksa nilai intercept pada persamaan (1.2) bernilai nol sehingga persamaan regresi berubah menjadi persamaan (1.3) berikut:

$$
\mathrm{d}_{12}=\mathrm{b} \mathrm{D} \mathrm{D}_{12}+\mathrm{e} \text {. }
$$

Proses iterasi berhenti jika nilai stress < 0.25 (Fauzi dan Anna 2005). Nilai Stress dirumuskan dalam persamaan (1.4) berikut:

Strees $=\sqrt{\frac{1}{m} \sum_{k=1}^{m}\left[\frac{\left.\sum_{i} \sum_{j}\left(D_{i j k}-d_{i j k}\right)^{2}\right]}{\sum_{i} \sum_{j} d_{i j k}^{2}}\right] . .}$

Kavanagh (2001) menyatakan bahwa iterasi berhenti jika stress $<0.005$. Nilai stress merupakan akar kuadrat nilai stress sehingga nilai stress juga bisa diperoleh dengan rumus berikut:

$$
\text { Stress }=\frac{M S S e_{i j k}}{M S S d_{i j k}} ;
$$

MSS = "mean sum of square" 
Tabel 1. Kategori status keberlanjutan pengembangan kawasan berdasarkan nilai indeks hasil analisis Rap-AGROSAPOT.

\begin{tabular}{cc}
\hline Nilai Indeks & Kategori \\
\hline $0-25$ & Buruk \\
$26-50$ & Kurang \\
$51-74$ & Cukup \\
$75-100$ & Baik \\
\hline
\end{tabular}

Sumber: Kavanagh, 2001

Nilai stress dan $\mathrm{R}^{2}$ (Malhotra, 2006). Model yang baik ditunjukkan dengan nilai Stress $<0.25$ dan $\mathrm{R}^{2}$ mendekati 1. Skala indeks keberlanjutan memiliki selang 0-100. Pada penelitian ini, ada empat kategori status keberlanjutan seperti yang terlihat pada Tabel 1.

Hasil lain yang diperoleh dalam analisis MDS adalah faktor pengungkit (leverage) yang merupakan faktor strategis dalam kegiatan pengelolaan di masa depan. Analisis leverage bertujuan melihat perubahan nilai error dari penentuan nilai keberlanjutan apabila salah satu atribut dikeluarkan dari analisis. Menurut Pitcher et al. (2002), analisis sensitivitas atau analisis leverage dilakukan terhadap seluruh atribut masing-masing dimensi. Perhitungan dilakukan dengan metode stepwise, yaitu membuang setiap atribut secara berurutan satu persatu kemudian menghitung nilai error atau root mean square (RMS) dibandingkan dengan nilai RMS yang dihasilkan pada saat seluruh atribut dianalisis. Metode ini dikenal sebagai metode Jackknife (Kavanagh, 2001). Evaluasi pengaruh galat (error) pada proses pendugaan nilai ordinasi analisis status keberlanjutan dilakukan dengan menggunakan analisis "Monte Carlo".

Analisis prospektif merupakan suatu upaya mengeksplorasi kemungkinan di masa depan (Evans, 2006). Hasil analisis memberikan informasi mengenai faktor kunci dan tujuan strategis apa saja yang berperan dalam pengembangan sistem sesuai dengan kebutuhan para pelaku dalam sistem tersebut. Penentuan faktor kunci dan tujuan strategis tersebut sangat penting, dan sepenuhnya merupakan pendapat dari pakar (expert).

Penentuan faktor kunci menggunakan analisis prospektif memiliki beberapa tahapan.
Pertama, faktor penting yang diperoleh dari analisis leverage dikumpulkan untuk dinilai oleh pakar terpilih. Kedua, Pengaruh antar faktor dalam sistem, dinilai (skor 0-3) oleh para pakar menggunakan matriks tertentu. Kemungkinan masa depan terbaik ditentukan berdasarkan hasil penentuan faktor kunci masa depan dari beberapa faktor yang sangat berpengaruh terhadap pengembangan sistem dan menuntut segera dilaksanakan tindakan. Hasil analisis berbagai faktor akan mengelompokkan faktor-faktor pada kelompok kuadran sebagai berikut: 1) Kuadran I (input), memuat faktor-faktor berpengaruh kuat dengan tingkat ketergantungan yang kurang kuat. Faktor pada kuadran ini merupakan faktor kunci dalam sistem. 2) Kuadran II (stakes), memuat faktor-faktor yang mempunyai pengaruh dan ketergantungan yang kuat. 3) Kuadran III (output), memuat faktorfaktor yang mempunyai pengaruh kecil, namun ketergantungannya tinggi. 4) Kuadran IV (unused), memuat faktor-faktor yang mempunyai pengaruh dan ketergantungan kecil (rendah).

\section{HASIL DAN PEMBAHASAN}

\section{Status Keberlanjutan Wilayah}

Berdasarkan hasil analisis menggunakan pendekatan Rapid Appraisal Agropolitan Sapi Potong (Rap-AGROSAPOT), nilai indeks keberlanjutan dimensi ekologi sebesar $41.61 \%$ dengan status kurang berkelanjutan, dimensi ekonomi $57.73 \%$ dengan status cukup berkelanjutan, dimensi hukum dan kelembagaan sebesar $75.46 \%$ dengan status baik, dimensi sosial budaya sebesar $58.05 \%$ dengan status cukup berkelanjutan serta dimensi infrastruktur dan teknologi sebesar $47.05 \%$ 
Tabel 2. Atribut-atribut sensitif yang berpengaruh terhadap indeks keberlanjutan wilayah peternakan sapi potong di Kabupaten Bondowoso untuk pengembangan kawasan agropolitan.

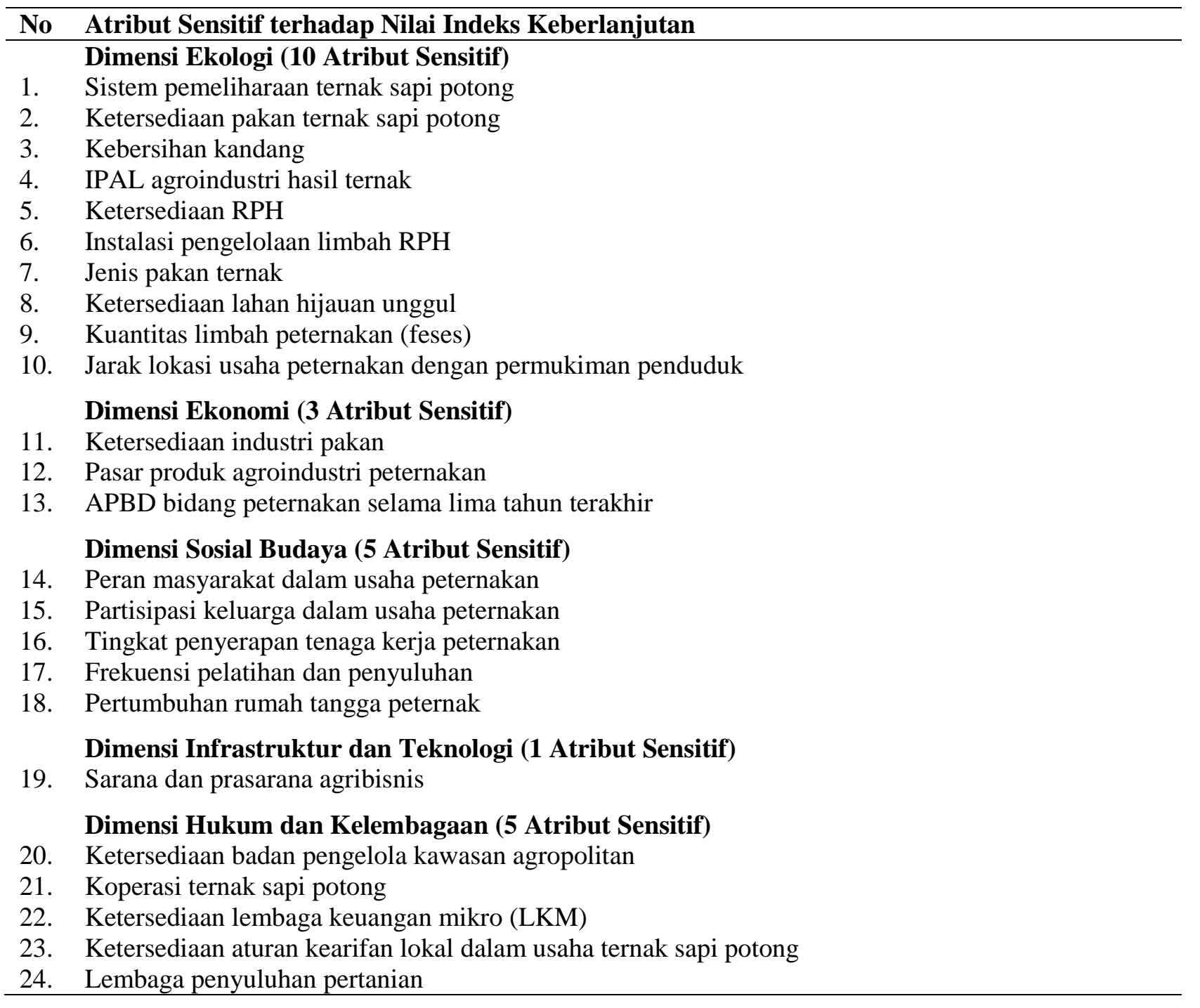

dengan status kurang berkelanjutan. Peningkatan nilai indeks keberlanjutan di masa depan dilakukan dengan perbaikan atribut sensitif berpengaruh pada nilai indeks keberlanjutan lima dimensi tersebut. Adapun nilai indeks lima dimensi keberlanjutan hasil analisis Rap-AGROSAPOT diperlihatkan pada Gambar 1.

Analisis sensitivitas terhadap lima dimensi, yaitu: dimensi ekologi, ekonomi, sosial budaya, infrastruktur/teknologi, dan hukum/kelembagaan dengan metode analisis leverage pada Rapfish memperlihatkan 24 (dua puluh empat) atribut sensitif terhadap nilai indeks keberlanjutan seperti terlihat pada Tabel 2 dan nilai indeks keberlanjutan serta hasil analisis leverage berdasarkan perubahan nilai root mean square (RMS) dapat dilihat pada Gambar 2.

\section{Multidimensi}

Hasil analisis Rap-AGROSAPOT secara multidimensi memperoleh nilai indeks keberlanjutan sebesar 54.78 dan termasuk dalam kategori cukup berkelanjutan. Nilai ini diperoleh berdasarkan penilaian 70 (tujuh puluh) atribut dari lima dimensi keberlanjutan. Hasil analisis Monte Carlo pada taraf kepercayaan 95\%, menunjukkan tidak adanya perbedaan besar antara hasil analisis RapAGROSAPOT (MDS) dengan uji Monte Carlo. Hal ini menunjukkan bahwa kesalahan dalam analisis kecil baik dalam hal pemberian 


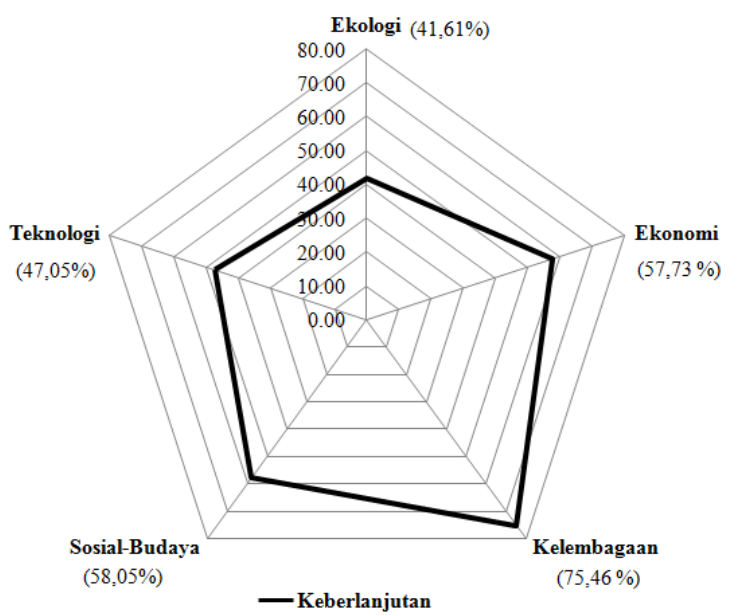

Gambar 1. Diagram layang (kite diagram) nilai indeks keberlanjutan wilayah Kabupaten Bondowoso.
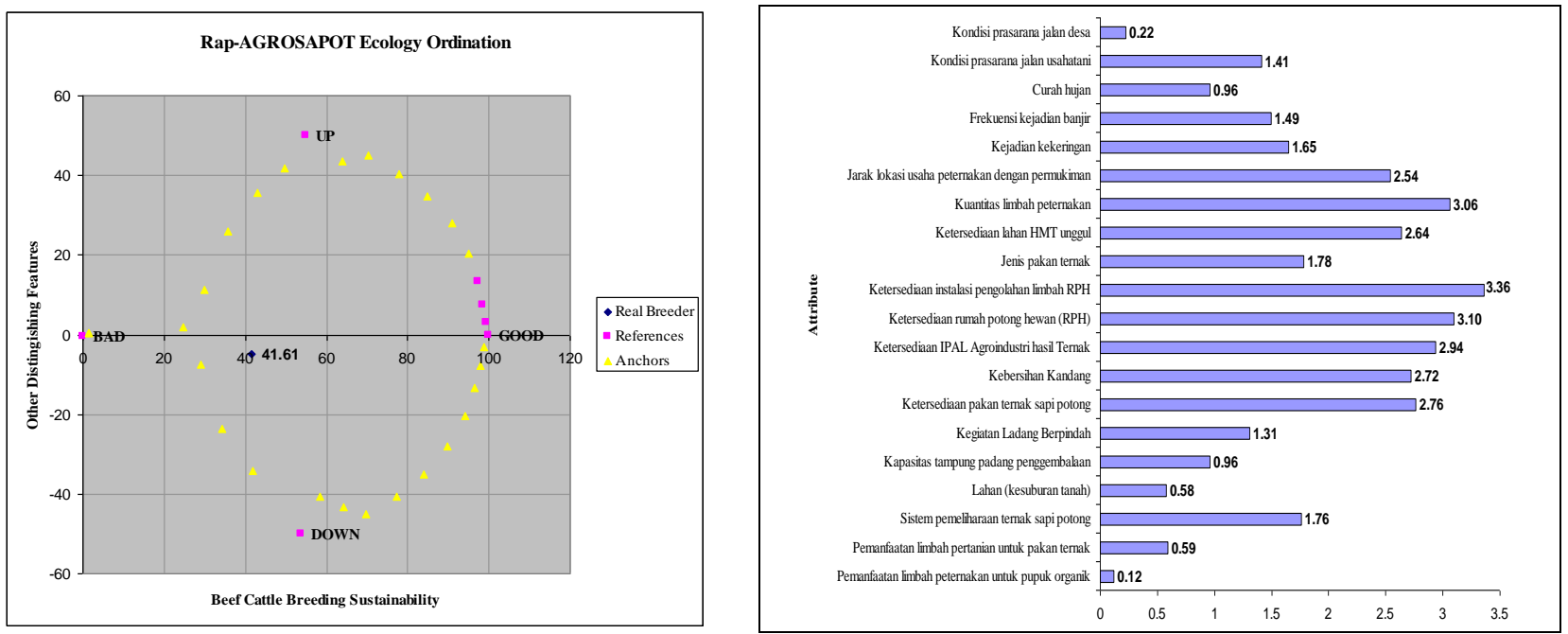

Gambar 2.a. Dimensi ekologi.
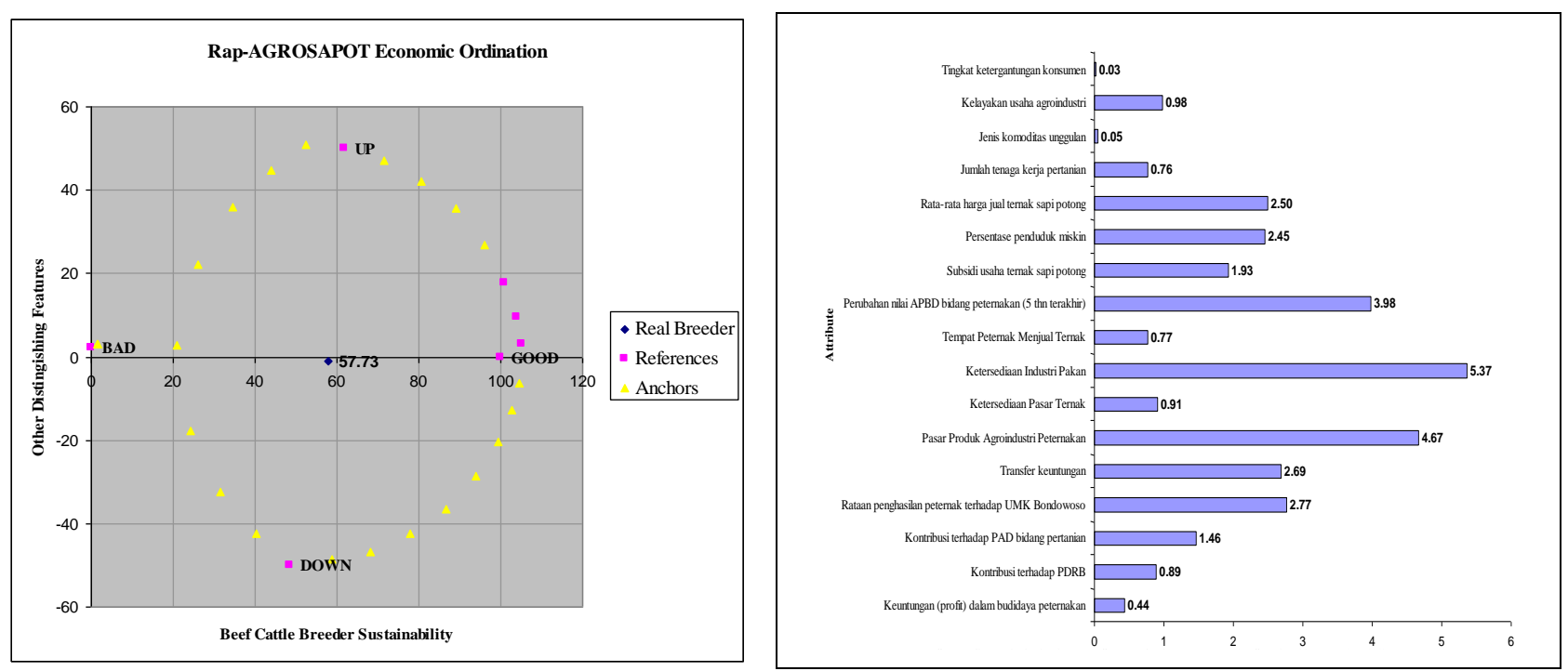

Gambar 2.b. Dimensi ekonomi. 

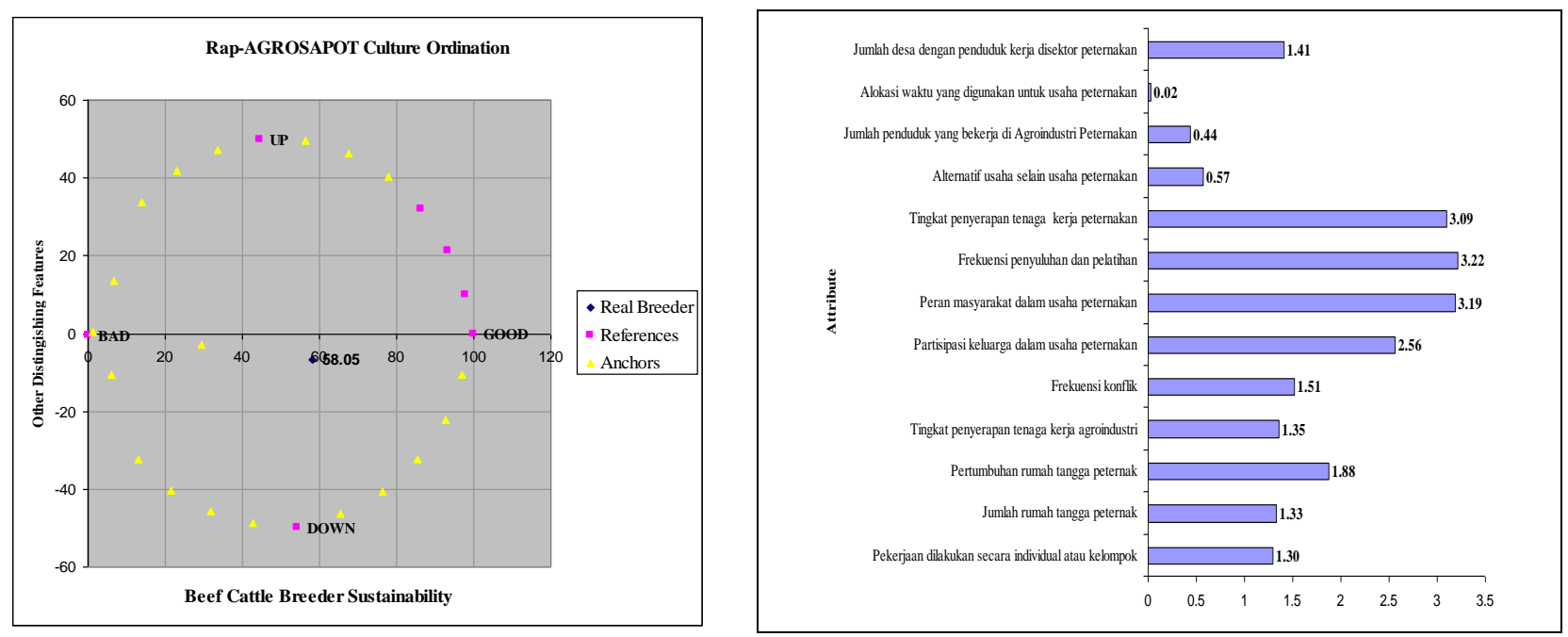

Gambar 2.c. Dimensi sosial budaya.
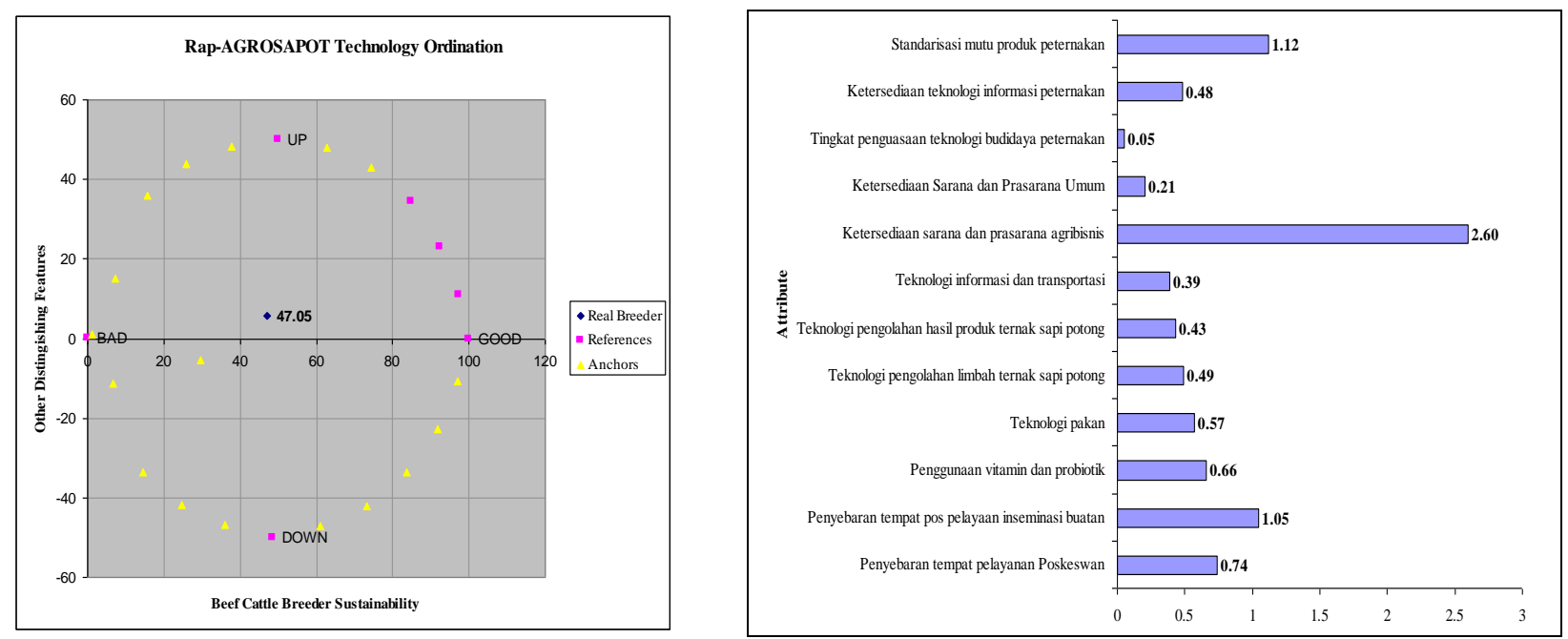

Gambar 2.d. Dimensi infrastruktur dan kelembagaan.
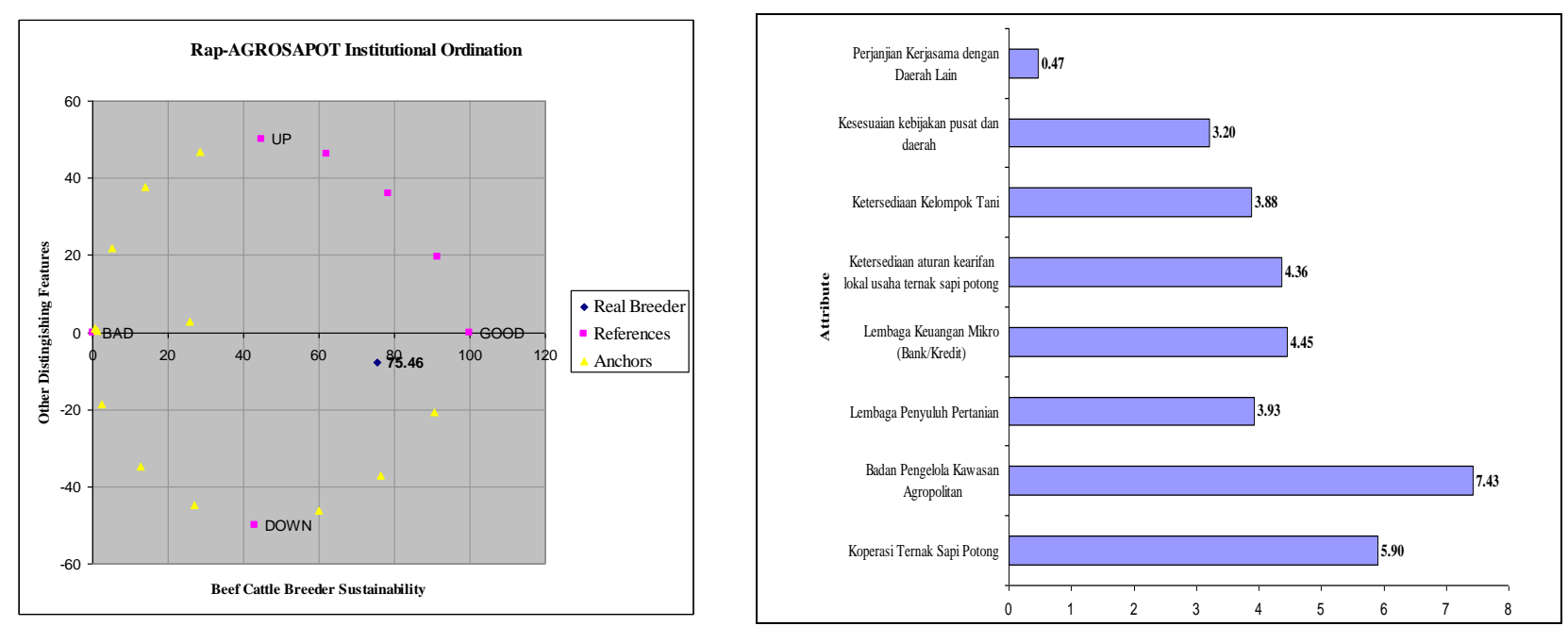

Gambar 2.e. Dimensi hukum dan kelembagaan.

Gambar 2. Nilai indeks keberlanjutan dan hasil analisis leverage berdasarkan perubahan nilai root mean square (RMS). Sumber : Data primer (diolah). 
Tabel 3. Perbedaan nilai indeks keberlanjutan analisis Monte Carlo dengan analisis RapAGROSAPOT.

\begin{tabular}{lccc}
\hline Dimensi Keberlanjutan & MDS & Monte Carlo & Perbedaan \\
\hline Ekologi & 41.61 & 42.76 & 1.15 \\
Ekonomi & 57.73 & 57.74 & 0.01 \\
Sosial-Budaya & 58.05 & 57.57 & 0.48 \\
Infrastruktur/Teknologi & 47.05 & 47.13 & 0.08 \\
Hukum/Kelembagaan & 75.46 & 72.36 & 3.10 \\
Multidimensi & 54.78 & 54.72 & 0.06 \\
\hline
\end{tabular}

skoring setiap atribut, variasi pemberian skoring karena perbedaan opini relatif kecil, dan proses analisis data yang dilakukan secara berulang-ulang stabil, serta kesalahan dalam menginput data dan data hilang mampu dihindari. Perbedaan nilai indeks keberlanjutan analisis MDS dan Monte Carlo seperti pada Tabel 3 .

Hasil analisis Rap-AGROSAPOT menunjukkan bahwa semua atribut yang dikaji terhadap status keberlanjutan wilayah Kabupaten Bondowoso untuk pengembangan kawasan agropolitan, cukup akurat sehingga memberikan hasil analisis yang baik dan dapat dipertanggungjawabkan. Hal ini terlihat dari nilai stress yang hanya berkisar antara $14 \%$ sampai $20 \%$ dan nilai koefisien determinasi $\left(\mathrm{R}^{2}\right)$ yang diperoleh berkisar antara 0.87 dan 0.95. Nilai tersebut sesuai dengan pendapat Fisheries (1999), yang menyatakan bahwa hasil analisis cukup memadai apabila nilai stress lebih kecil dari nilai 0.25 (25\%) dan nilai koefisien determinasi $\left(\mathrm{R}^{2}\right)$ mendekati nilai 1. Adapun nilai stress dan koefisien determinasi dapat dilihat pada Tabel 4 .

\section{Analisis Prospektif Pengembangan Kawasan Agropolitan}

Berdasarkan hasil analisis leverage diperoleh 24 atribut sensitif dan selanjutnya diajukan kepada pakar untuk dinilai dan dianalisis prospektif. Hasil analisis prospektif menghasilkan 5 (lima) faktor kunci/penentu, yaitu: 1) ketersediaan sarana dan prasarana agribisnis peternakan, 2) sistem pemeliharaan ternak, 3) ketersediaan pasar agroindustri peternakan, 4) ketersediaan industri pakan, dan 5) koperasi ternak sapi potong (Gambar 3). Hasil analisis tersebut mengindikasikan bahwa kelima atribut tersebut perlu dikelola dengan baik agar terwujud pengembangan kawasan agropolitan berkelanjutan berbasis peternakan sapi potong di Kabupaten Bondowoso.

Ketersediaan sarana dan prasarana agribisnis peternakan di Kabupaten Bondowoso dikategorikan minim, padahal atribut tersebut merupakan salah satu atribut kunci/penentu dalam menentukan indeks keberlanjutan. Hal ini disebabkan atribut tersebut memiliki efek domino (multiplier effects) terhadap atribut-atribut yang penentu keberlanjutan pengembangan kawasan lainnya. Menurut Saragih (2000), kegiatan usaha budidaya peternakan merupakan bagian dari sistem agribisnis peternakan yang mencakup empat subsistem, yaitu: subsistem agribisnis hulu (upstream off-farm agribusiness); subsistem agribisnis budidaya peternakan (on-farm agribusiness); subsistem agribisnis hilir (downstream off-farm agribusiness); dan subsistem jasa penunjang (supporting institution). Dengan demikian sistem agribisnis peternakan merupakan kegiatan yang mengintegrasikan pembangunan sektor pertanian secara sinergis (dalam arti luas) dengan industri dan jasa dalam suatu kawasan industri peternakan yang mencakup empat subsistem.

Sistem pemeliharaan ternak pada umumnya masih bersifat tradisional dan semi intensif. Sebagian besar ternak sapi potong diikat pada pohon yang berada dekat dengan rumah dan sebagian lainnya dikandangkan. Pakan yang diberikan pada umumnya rumput lapangan yang dicampur dengan rumput unggul. Sistem pemeliharaan ternak seperti ini 
Tabel 4. Hasil analisis Rap-AGROSAPOT untuk nilai stress dan koefisien determinasi $\left(\mathrm{R}^{2}\right)$.

\begin{tabular}{lrrrrrr}
\hline Parameter & Ekologi & Ekonomi & Sosial & Teknologi & Hukum & Multi \\
\hline Stress & 0.15 & 0.14 & 0.14 & 0.14 & 0.13 & 0.20 \\
$\mathrm{R}^{2}$ & 0.87 & 0.88 & 0.92 & 0.93 & 0.95 & 0.93 \\
Iterasi & 4 & 4 & 3 & 3 & 3 & 4 \\
\hline
\end{tabular}

sudah tentu kurang maksimal dalam memberikan penerimaan terhadap peternak. Kabupaten Bondowoso yang memiliki potensi pertanian dan perkebunan yang cukup potensial, sangat cocok dalam menerapkan sistem pemeliharaan ternak sapi potong secara terpadu dengan tanaman pangan dan perkebunan. Sistem pemeliharaan ternak terpadu akan mendorong terjadinya efisiensi produksi, pencapaian produksi yang optimal, peningkatan diversifikasi usaha dan peningkatan daya saing produk pertanian yang dihasilkan, sekaligus mempertahankan dan melestarikan sumberdaya lahan (Diwyanto dan Handiwirawan 2004). Sistem integrasi ternak dangan tanaman merupakan salah satu kegiatan pertanian organik (organic farming) berbasis teknologi, dengan memanfaatkan sumberdaya lokal yang didaur ulang secara efektif. Sistem ini melibatkan paling tidak tiga jenis kegiatan usaha tani yang saling berkaitan, yaitu: (1) budidaya ternak sapi potong, (2) budidaya tanaman pangan atau perkebunan, dan (3) pengolahan limbah pertanian dan ternak.

Ketersediaan pasar produk agroindustri peternakan akan memacu terciptanya/tersedianya ketersediaan industri pengolahan hasil ternak, seperti: industri pengolahan daging sapi, industri pengolahan kulit, dan industri pupuk organik yang akan membutuhkan bahan baku ternak sapi potong yang cukup banyak. Selain itu, akan terjadi peningkatan kebutuhan tenaga kerja, rumah potong hewan, dan industri pakan ternak di kawasan ini. Keberadaan industri pengolahan hasil ternak ini juga akan mempengaruhi pasar produk hasil peternakan dan berdampak banyak (multiplier effects) terhadap perkembangan kawasan dan pada akhirnya akan meningkatkan produk domestik regional bruto (PDRB). Oleh sebab itu, Ketersediaan pasar produk agroindustri peternakan sangat membantu kawasan ini dalam rangka memajukan pertumbuhan kawasan dan meningkatkan PDRB daerah ini. Keberadaan industri pengolahan hasil ternak juga akan meningkatkan kegiatan agribisnis komoditas unggulan lokal, yang saling mendukung dan menguatkan termasuk industri kecil, pengolahan hasil, jasa pemasaran dan agrowisata dengan mengoptimalkan manfaat sumberdaya alam, secara efisien dan ekonomis, sehingga tidak ada limbah yang terbuang atau yang yang tidak dimanfaatkan untuk kesejahteraan masyarakat (usaha pertanian terpadu tanpa limbah).

Dalam rangka membangun kawasan agropolitan berbasis peternakan sapi potong yang maju, kehadiran koperasi sangat dibutuhkan untuk memudahkan masyarakat mencari suntikan dana/modal, menampung produk agroindustri peternakan dan memasarkannya, serta lebih mempermudah dalam pelayanan pembiayaan kegiatan ekonomi mikro masyarakat setempat. Koperasi yang terbentuk sebaiknya merupakan upaya kesadaran dan partisipasi dari masyarakat dalam menjalankan program pengembangan untuk kepentingannya sendiri. Pada pola ini masyarakatlah yang memilki inisiatif dan berperan penuh pada kegiatan-kegiatan mereka, sehingga keberhasilannya sangat ditentukan dari rasa tanggung jawab dari masyarakat itu sendiri. Langkah awal dari pembentukan koperasi ini harus ada pendampingan, pengorganisasian, dan pemberdayaan masyarakat.

\section{KESIMPULAN}

Hasil analisis status keberlanjutan wilayah berbasiskan peternakan sapi potong ditinjau dari lima dimensi keberlanjutan menunjukkan bahwa keberlanjutan dari dimensi ekologi dan ekonomi tergolong kurang berkelanjutan, keberlanjutan dari dimensi infrastruktur tekno- 


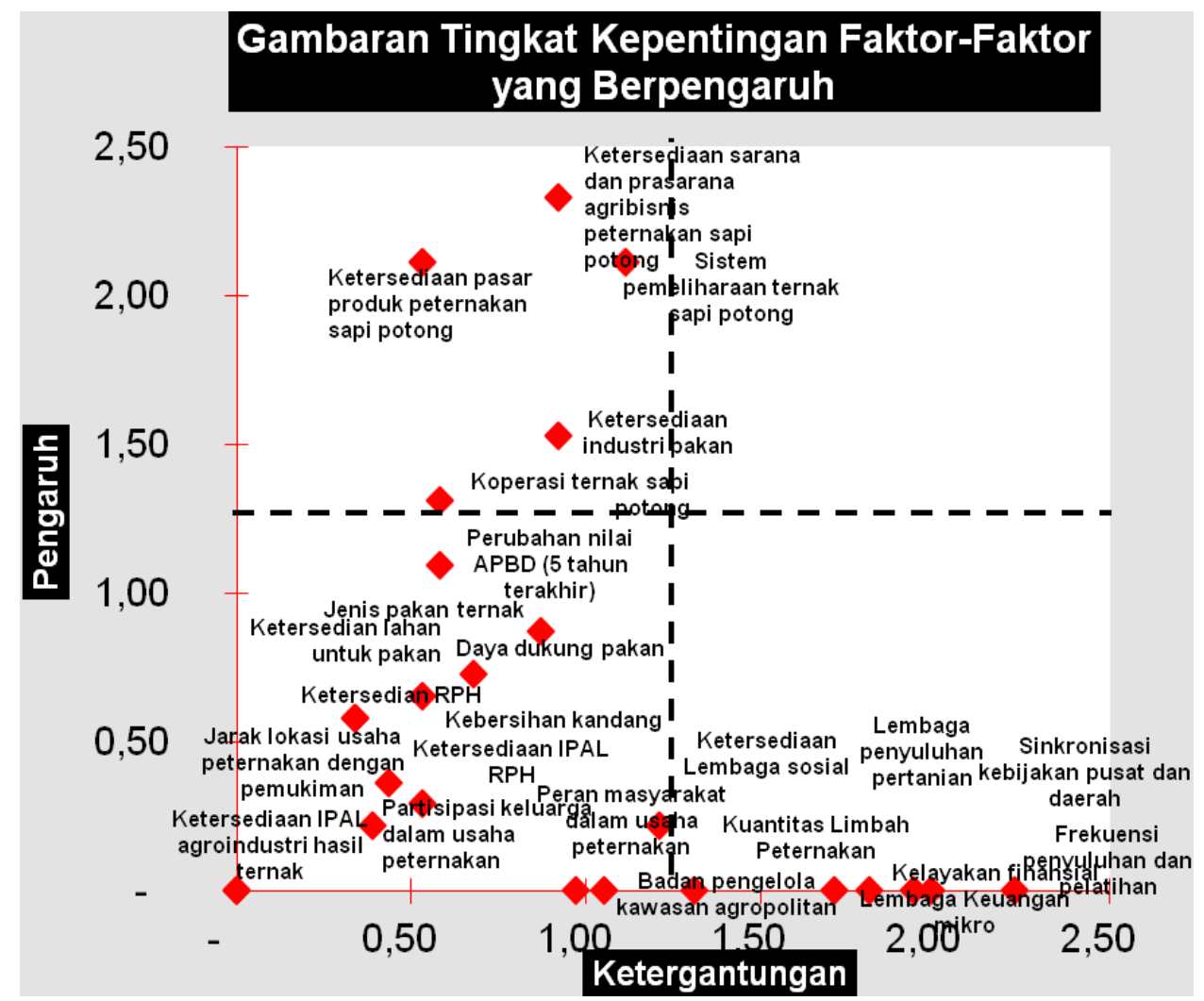

Gambar 3. Hasil analisis prospektif faktor kunci/dominan yang berpengaruh pada keberlanjutan peternakan sapi potong.

logi dan sosial budaya tergolong cukup berkelanjutan serta keberlanjutan dari dimensi hukum kelembagaan tergolong baik. Status keberlanjutan secara multidimensi tergolong dalam status cukup berkelanjutan. Berdasarkan hasil analisis prospektif dari 24 atribut sensitif diperoleh 5 (lima) faktor kunci/ penentu yang memiliki pengaruh kuat dan tingkat ketergantungan antar faktor yang rendah, yaitu: 1. ketersediaan sarana dan prasarana agribisnis; 2. sistem pemeliharaan ternak sapi potong; 3. ketersediaan pasar produk sapi potong; 4. Ketersediaan industri pakan, dan 5. koperasi ternak sapi potong. Faktor kunci tersebut merupakan bagianbagian penting dari subsistem agribisnis (hulu, budidaya, dan hilir).

\section{DAFTAR PUSTAKA}

Barlas, Y. 2005. Multiple test for validation of system dynamics type of simulation models. European Journal of Operational Research 42 (1): 59 - 87.
[BPS] Badan Pusat Statistik. 2012. Kabupaten Bondowoso dalam Angka 2012. Bondowoso (ID): Badan Pusat Statistika Kabupaten Bondowoso.

[Deptan] Departemen Pertanian. 2002. Pedoman Umum Pengembangan Kawasan Agropolitan dan Pedoman Program Rintisan Pengembangan Kawasan Agropolitan. Jakarta (ID): Badan Pengembangan Sumberdaya Manusia Pertanian.

Diwyanto K, Prawiradiputra BR, Lubis D. 2002. Integrasi tanaman ternak dalam pengembangan agribisnis yang berdayasaing, berkelanjutan dan berkerakyatan. Wartazoa 12(1):1-8.

Evans, P. 2006. Government action social capital and development: Reviewing the evidance of synergy. Word Development 24 (6): 1119 - 1132.

Fauzi A., dan Anna S. 2005. Pemodelan Sumber Daya Perikanan dan Lautan 
untuk Analisis Kebijakan. Jakarta (ID): Gramedia Pustaka Utama.

Fisheries. 1999. Rapfish Software for Excel. Fisheries Centre Research Reports.

Gao, F., M. Li and Y. Nakamori. 2008. Critical systems thinking as a way to manage knowledge. System Dinamics Review 20 (1): 3 - 19.

Hidayanto M., S. Supiandi, S. Yahya, dan L. I. Amien. 2009. Analisis keberlanjutan perkebunan kakao rakyat di kawasan perbatasan Pulau Sebatik, Kabupaten Nunukan, Propinsi Kalimantan Timur. Jurnal Agro Ekonomi (JAE), Vol. 27 (2): 213-229.

Kavanagh P. 2001. Rapid Appraisal of Fisheries (Rapfish) Project. Rapfish Software Description (for Microsoft Excel). Vancouver (CA): University of British Columbia, Fishries Centre.

Pitcher TJ. 1999. Rapfish: A Rapid Appraisal Technique for Fisheries and Its Application to The Code of Conduct for
Responsible Fisheries. Rome (IT): FAO $\mathrm{UN}$.

Saragih B. 2000. Agribisnis Berbasis Peternakan. Bogor (ID): USESE Foundation dan Pusat Studi Pembangunan IPB.

Saragih, B dan T. Sipayung. 2002. Biological utilization in developmentalism and environmentalism. Paper presented at the International Seminar and Resources Accounting Environmental Economic Held in Yogyakarta Indonesia. April 29.

Suyitman, S.H. Sutjahjo, C. Herison, dan Muladno. 2009. Status keberlanjutan wilayah berbasis peternakan di Kabupaten Situbondo. Jurnal Agro Ekonomi (JAE), Vol. 27 (2): 165-191.

Suyitman, S.H. Sutjahjo, dan A. Djulardi. 2012. Status keberlanjutan wilayah berbasis peternakan sapi potong terpadu di Kabupaten Lima Puluh Kota Propinsi Sumatera Barat. Jurnal Peternakan Indonesia (JPI), Vol. 14 (1): 318-336. 